\title{
Anal Cancer pM1 TNM Finding v8
}

National Cancer Institute

\section{Source}

National Cancer Institute. Anal Cancer pM1 TNM Finding v8. NCI Thesaurus. Code C133769.

Anal cancer with distant metastasis. (from AJCC 8th Ed.) 